\title{
Alkali and Alkaline Earth Perchlorate and Picrate Complexes with Some Macrocyclic Polyethers
}

\author{
LJ. Tư̌eK ${ }^{1}$ and H. MeIder-GoričAN \\ Department of Physical Chemistry, Institute Rudjer Bošković, Zagreb, Yugoslavia \\ and \\ P. R. DANesi \\ C.N.E.N. Laboratorio Chimica Fisica, C.S.N. Casaccia, Rome, Italy \\ (Z. Naturforsch. 31 b, 330-335 [1976]; received October 10, 1975)
}

Macrocyclic Polyether Complexes, Alkali Perchlorate, Picrate Complexes, Alkaline Earth Perchlorate, Picrate Complexes

\begin{abstract}
Crystalline complexes of some alkali and alkaline earth perchlorates and picrates with macrocyclic polyethers have been synthesized. With the alkyl substituted aromatic macrocyclic polyethers bis(3,5-di-tert-butylbenzo)-18-crown-6 and bis(4-hexadecylbenzo)-18crown- 6 it was not possible to isolate all the complexes in the crystalline form. In fact the steric hindrance, caused by the alkyl substituents, affects the stability of the complexes and hinders the possibility of isolation. It has been observed that also the molecular structure and the electronic configuration of the anion are important factors in determing the formation of crystalline complexes. The complexes obtained were identified and characterized by elemental analysis, IR, UV and ${ }^{1} \mathrm{H}$ NMR spectra, conductivity and $\mathrm{x}$-ray powder analysis.
\end{abstract}

\section{Introduction}

In the past few years there has been considerable interest in the field of synthesis and complex forming properties of macrocyclic polyethers ${ }^{1-18}$. Macrocyclic polyethers can form complexes with many salts which are stable both in solution and in the solid state. The complexes of the macrocyclic polyethers with salts of alkali and alkaline earth metal cations have drawn particular attention ${ }^{7-11}$. The bonds in the complexes are attributed to iondipol interactions between the positively charged cation and the negative end of the $\mathrm{C}-\mathrm{O}$ dipole of the polyether ring. Different workers have measured the extent of complex formation between macrocyclic polyethers and picrates and perchlorates of alkali cations in different solvents ${ }^{14,15}$, but only few of these complexes have been isolated in the crystalline form ${ }^{10}$.

In the present work we have prepared macrocyclic polyether complexes of sodium, potassium,

Requests for reprints should be sent to Dr. LJ. TUŠEK, Institute Rudjer Bošković, P. B. 1016, Y-41001 Zagreb, Yugoslavia. rubidium, calcium, strontium and barium using perchlorate and picrate as counterions. The influence of the size of the internal hole of the macrocyclic polyether, the metal ionic diameter, the presence of neutral alkyl substituents on the benzene ring of the macrocyclic polyether, and the charge density of metal cation and anion, on the formation of the crystalline salt complexes from methanolic solutions, has been investigated and discussed. The structure and the names (together with abbreviations used in this paper) of the studied macrocyclic polyethers are shown in Fig. 1.

\section{Experimental Section}

\section{Materials}

Macrocyclic polyethers were prepared as previously described ${ }^{2,16}$. Metal perchlorates (Merck) were used without further purification. Metal picrates were prepared according to the standard procedures. All other reagents and solvents used were analytical grade purity products.

\section{Preparation of complexes}

Complexes were all prepared in methanol. Two different methods have been used. 

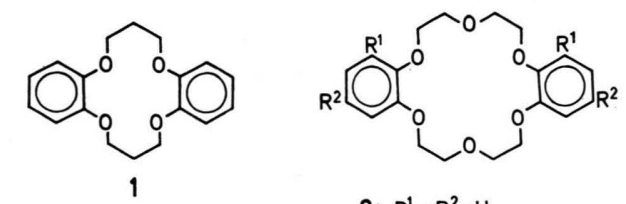

2: $R^{1}=R^{2}=H$

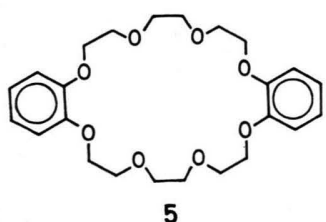

3: $R^{1}=R^{2}=B u^{t}$

4: $\mathrm{R}^{1}=\mathrm{H}_{;} \mathrm{R}^{2}=\mathrm{C}_{16} \mathrm{H}_{33}$

Fig. 1. Structural formulae of the macrocyclic polyethers. The systematic and "crown" names are:

1: 7,8,16,17-tetrahydro-6 H,15 H-dibenzo[b,i]$[1,4,8,11]$-tetraoxacyclotetradecin(dibenzo-14crown-4);

2 : $6,7,9,10,17,18,20,21$-octahydrodibenzo[b,k]$[1,4,7,10,13,16]$ hexaoxacyclooctadecin(dibenzo-18-crown-6);

3: 1,3,13,15-tetra(1,1-dimethylethyl)$6,7,9,10,17,18,20,21$-octahydrodibenzo[b,k]$[1,4,7,10,13,16]$ hexaoxacyclooctadecin[bis(3,5-di-tert-butylbenzo)-18-crown-6];

4: 2,14-dihexadecyl-6,7,9,10,17,18,20,21octahydrodibenzo[b,k]-

$[1,4,7,10,13,16]$ hexaoxacyclooctadecin[bis(4-hexadecylbenzo)-18-crown-6] and

5 : $6,7,9,10,12,13,20,21,23,24,26,27$-dodecahydrodibenzo[b,n] $[1,4,7,10,13,16,19,22]$ octaoxacyclotetracosin(dibenzo-24-crown-8).

Method 1: An equal number of moles of polyether and alkali or alkaline earth metal salts were dissolved in methanol and boiled under reflux for 1-3 $\mathrm{h}$ with vigorous stirring. The clear hot solution was filtered and allowed to stand at room temperature. The complex gradually precipitated as a crystalline solid either on cooling, or by removal of solvent. The precipitate was filtered off, washed with cold methanol, and dried in vacuum. The homogeneity of the crystals was ascertained by microscope.

Method 2: The metal salt was dissolved in the minimum quantity of methanol and added dropwise, under stirring, to the hot solution of macrocyclic polyether in methanol. A crystalline precipitate was formed almost immediately. After standing for $\mathbf{l ~ h}$ at room temperature, this precipitate was filtered off, washed with warm methanol, and dried in vacuum.

Only few crystalline complexes could be recrystallized from methanol or ethanol. In general the uncomplexed polyether was recovered after recrystallization. All complexes obtained were dried under vacuum without decomposition, giving stable anhydrous complexes as confirmed by elemental and thermogravimetric analyses, and spectral data.

By standing in air some complexes became hydrated. This fact is in agreement with previous studies with macrocyclic polyether complexes of alkali and alkaline earth metals which have shown that, with some cations and anions hydrated complexes are formed ${ }^{7-9}$.

The complexes of macrocyclic polyethers 1-5 with the metal perchlorates are colourless, while those with the metal picrates are yellow to orange compounds. Nearly all the perchlorate complexes were found well crystalline, showing a clear x-ray powder diffraction pattern. A clear pattern was instead obtained only for some of the picrate complexes.

\section{Instrumentation and analysis}

IR spectra were recorded on $\mathrm{KBr}$ pellets and Nujol mulls using a Perkin-Elmer spectrophotometer Model 257, in the region $4000-650 \mathrm{~cm}^{-1}$. ${ }^{1} \mathrm{H}$ NMR spectra were obtained in $\mathrm{CDCl}_{3}$ solutions and recorded on a Varian A-60 A spectrometer. TMS was used as internal standard. UV spectra were obtained in methanolic solutions with a Perkin-Elmer M-124 spectrophotometer. Conductivity measurements were performed using a CD $7 \mathrm{~A}$ conductivity bridge (Tacussel Electronique, France). The molar conductance was determined at $25^{\circ} \mathrm{C}$ at the concentrations of $10^{-3} \mathrm{M}$ and $10^{-4} \mathrm{M}$. X-ray powder photographs were taken in $0.3 \mathrm{~mm}$ capillaries with a Philips $114.6 \mathrm{~mm}$ camera and using the $\mathrm{Cu} \mathrm{K} \alpha$ radiation. The exposure time was $3 \mathrm{~h}$. Thermogravimetric measurements were performed using the Cahn RG electro-micro balance with a heating rate of $2{ }^{\circ} \mathrm{C} / \mathrm{min}$, in an atmosphere of static air.

The carbon, hydrogen, and nitrogen analysis were performed by the Microanalytical Laboratory of the Institute Rudjer Bošković. Alkali metals and calcium were determined by flame photometry. Strontium and barium were determined as sulphates.

\section{Results and Discussion}

The physical properties and the results of the elemental analysis of the well defined complexes, as well as the preparation methods, are given in Table I.

The dimensions of the polyether hole and of the metal cation are responsible to a large extent for the remarkable differences in the complexing behaviour of the macrocyclic polyethers 1-5. The possibility of conformational changes in the polyether ring, accompanying the formation of the equilibrium cavity necessary for accomodating cations of various size, is also a very important factor to be taken into account in the complex formation process. 
Table I. Properties and analytical data of complexes.

\begin{tabular}{|c|c|c|c|c|c|c|c|c|c|c|c|c|}
\hline \multirow[b]{2}{*}{ Complex } & \multirow[b]{2}{*}{ Method } & \multirow[b]{2}{*}{$\begin{array}{l}\text { m.p. } \\
{\left[{ }^{\circ} \mathrm{C}\right]}\end{array}$} & \multirow[b]{2}{*}{$\begin{array}{l}\text { Yield } \\
{[\%]}\end{array}$} & \multirow[b]{2}{*}{$\begin{array}{l}\text { Molar con- } \\
\text { ductanced }\end{array}$} & \multirow[b]{2}{*}{$\mathrm{C}$} & \multicolumn{7}{|c|}{ Analysis [\%] } \\
\hline & & & & & & $\mathrm{H}$ & $\begin{array}{c}\text { alcd } \\
\mathrm{N}\end{array}$ & Metal & $\mathrm{C}$ & $\mathrm{H}$ & $\begin{array}{c}\text { Found } \\
\mathrm{N}\end{array}$ & Metal \\
\hline $\left.\mathrm{Na}_{2(} \mathbf{1}\right)_{3}$ (pic. $)_{2}{ }^{\mathrm{a}}$ & 1 & $269-271$ & 87 & $70^{\mathrm{e}}$ & 56.67 & 4.62 & 6.01 & 3.29 & 56.53 & 4.88 & 6.11 & 3.16 \\
\hline $\mathrm{Na}(\mathbf{2}) \mathrm{ClO}_{4}$ & 1 & $218-219$ & 99 & 88 & 49.73 & 5.01 & & 4.77 & 49.68 & 4.82 & & 4.36 \\
\hline $\mathrm{Na}(2)$ pic. & 1 & $158-159$ & 48 & 70 & 51.04 & 4.29 & 6.87 & 3.76 & 50.97 & 4.53 & 6.86 & 3.46 \\
\hline $\mathrm{K}(2) \mathrm{ClO}_{4}$ & 1 & $221-222$ & 81 & 90 & 48.12 & 4.85 & & 7.84 & 47.76 & 5.04 & & 7.75 \\
\hline K(2) pic. & 1 & $156-157$ & 92 & 74 & 49.73 & 4.18 & 6.70 & 6.23 & 49.50 & 4.21 & 6.98 & 5.95 \\
\hline $\mathrm{Rb}(\mathbf{2}) \mathrm{ClO}_{4}$ & 1 & $167-169$ & 47 & 105 & 44.03 & 4.44 & & 15.67 & 44.34 & 4.68 & & 16.16 \\
\hline $\mathrm{Rb}(\mathbf{2})$ pic. & ] & $220-222$ & 83 & 77 & 46.31 & 3.89 & 6.24 & 12.68 & 46.13 & 3.58 & 6.51 & 12.92 \\
\hline $\mathrm{Ca}(\mathbf{2})\left(\mathrm{ClO}_{4}\right)_{2}$ & 1 & $>300$ & 84 & 186 & 40.05 & 4.04 & & 6.69 & 40.25 & 4.25 & & 6.46 \\
\hline $\mathrm{Ca}(\mathbf{2})$ (pic.) 2 & 1 & $289-291^{\mathrm{c}}$ & 92 & $80(145)$ & 44.84 & 3.30 & 9.81 & 4.68 & 45.09 & 3.46 & 10.08 & 4.65 \\
\hline $\mathrm{Sr}(2)\left(\mathrm{ClO}_{4}\right)_{2}$ & 2 & $>300$ & 81 & 180 & 37.11 & 3.74 & & 13.55 & 36.89 & 3.70 & & 13.21 \\
\hline $\operatorname{Sr}(2)$ (pic. $)_{2}$ & 1 & $280-282$ & 57 & $83(149)$ & 42.48 & 3.12 & 9.30 & 9.69 & 42.72 & 3.26 & 9.58 & 9.63 \\
\hline $\mathrm{Ba}(2)\left(\mathrm{ClO}_{4}\right)_{2}$ & 1 & $>300$ & 79 & 176 & 34.46 & 3.47 & & 19.72 & 34.60 & 3.71 & & 19.68 \\
\hline $\mathrm{Ba}(2)$ (pic.) 2 & 2 & $286-287$ & 80 & $\mathbf{f}$ & 40.27 & 2.96 & 8.81 & 14.40 & 40.31 & 3.12 & 8.58 & 14.58 \\
\hline $\mathrm{Na}(3)$ pic. & 1 & $135-136$ & 32 & 80 & 60.32 & 7.00 & 5.03 & 2.75 & 60.15 & 7.10 & 5.01 & 2.59 \\
\hline K(3) pic. & 1 & $112^{\mathrm{c}}$ & 43 & 93 & 8 & 6.86 & 4.93 & 4.59 & 58.88 & 6.82 & 4.66 & 4.37 \\
\hline $\mathrm{Ba}(\mathbf{3})$ (pic. $)_{2}{ }^{\mathrm{a}}$ & 1 & $287-288$ & 66 & $89(150)$ & 48.90 & 5.13 & 7.14 & 11.66 & 48.77 & 5.24 & 7.16 & 11.75 \\
\hline $\mathrm{Ba}(4)$ (pic.) ${ }_{2}$ & 1 & 130 & 50 & $\mathbf{P}$ & 54.80 & 6.63 & 5.97 & 9.80 & 54.64 & 6.35 & 6.20 & 9.92 \\
\hline $\mathrm{Na}(5) \mathrm{ClO}_{4}$ & 1 & $150-151$ & 67 & 104 & 50.46 & 5.65 & & 4.03 & 50.21 & 5.38 & & 3.80 \\
\hline $\mathrm{Na}(5)$ pic. & 1 & $144-145$ & 72 & 82 & 51.48 & 4.90 & 6.01 & 3.29 & 51.32 & 4.61 & 5.87 & 3.49 \\
\hline K(5) pic. & 1 & $130^{\mathrm{c}}$ & 64 & 80 & 50.32 & 4.79 & 5.87 & 5.47 & 50.10 & 4.84 & 6.05 & 5.44 \\
\hline $\mathrm{Rb}(\boldsymbol{5})$ pic. & 1 & $115-116$ & 41 & 80 & 47.26 & 4.50 & 5.52 & 11.22 & 47.56 & 4.48 & 5.52 & 11.36 \\
\hline $\mathrm{Sr}(\mathbf{5})\left(\mathrm{ClO}_{4}\right)_{2} \mathrm{~b}$ & 1 & 218 & 71 & 187 & 39.19 & 4.39 & & 11.93 & 38.87 & 4.41 & & 11.69 \\
\hline $\operatorname{Sr}(\mathbf{5})$ (pic.) $)_{2}$ & 1 & $205-206$ & 73 & $83(152)$ & 43.55 & 3.66 & 8.47 & 8.83 & 43.87 & 3.72 & 8.19 & 8.83 \\
\hline $\mathrm{Ba}(5)\left(\mathrm{ClO}_{4}\right)_{2}$ & 1 & $256-257$ & 58 & 177 & 36.71 & 4.11 & & 17.51 & 37.14 & 4.25 & & 17.76 \\
\hline $\mathrm{Ba}(\mathbf{5})$ (pic.) ${ }_{2}$ & 1 & 189-192 & 62 & P & 41.47 & 3.48 & 8.07 & 13.19 & 41.58 & 3.36 & 7.88 & 13.14 \\
\hline
\end{tabular}

a Recrystallized from methanol; b Recrystallized from ethanol; ${ }^{\mathrm{c}}$ Melting with decomposition; d Concentration $10^{-3}\left(10^{-4}\right) \mathrm{M}$ in methanol at $25^{\circ} \mathrm{C}\left(\mathrm{in} \mathrm{cm}^{2} \mathrm{ohm}^{-1} \mathrm{~mol}^{-1}\right)$; e Values relative to (Na pic.) $(\mathrm{I})_{3 / 2} ;^{\mathrm{P}} \mathrm{Too}$ insoluble for measurements.

The polyether ring of dibenzo-14-crown-4 (1) is large enough only for interacting with sodium and the weakly complexing calcium cation. Reaction of sodium picrate with 1 gave a $3: 2$ (polyether:metal) complex. After recrystallization from methanol, a complex with the same stoichiometry was obtained. Complexes with sodium perchlorate and calcium salts could not be isolated.

Dibenzo-18-crown-6 (2) forms 1: 1 complexes with all perchlorate and picrate metal salts. Previous investigations have shown that this polyether can react with rubidium isothiocyanate giving $2: 1$ and $3: 2$ (polyether:metal) complexes ${ }^{3,17}$. We have instead found that the reaction of rubidium perchlorate and picrate with 2 gave only $1: 1$ complexes. Moreover the calcium and strontium complexes of polyether 2 have been found to have basically the same pattern in x-ray powder photographs indicating that when the anion is the same the complexes are isomorphous.

Alkyl substituted macrocyclic polyethers 3 and 4 form complexes too, but we failed to isolate the complexes of all metal perchlorates and of some picrates. Some spectral evidences (see later) and distribution studies ${ }^{18}$, however confirmed that complex formation can take place in solution. For polyether 3 the reason for this failure can be attributed to the steric hindrance of the bulky tert. butyl groups. For polyether 4, besides the steric effect of the long hexadecyl chains, the low solubility of the polyether in methanol contributes to this failure. Sodium, potassium and barium picrate complexes with 3 and the barium picrate complex with 4 have been instead isolated.

The difficulty to isolate crystalline complexes of the metal perchlorates can be explained considering the strong hydrogen bonding between perchlorate and methanol, and the high lattice energy of the perchlorate salts. Consequently the metal cation can not produce the necessary polarization of the macrocyclic molecule. On the other hand when the picrate anion is present some degree of charge transfer between the cation and the anion can take place increasing the stability of the complex. Therefore crystalline complexes of metal picrates are more easily formed than those of metal perchlorates. Further it is worth mentioning that, as proved by the diffuse $\mathrm{x}$-ray powder diffraction 
patterns, the complexes of polyethers 3 and 4 have been found to have a low degree of crystallinity.

Polyether 5, with a 24-membered ring, forms 1:1 crystalline complexes with sodium, strontium and barium perchlorates and with all picrate salts except calcium. The lower complexing power of calcium is probably due to its strong solvation. The comparatively high complexing ability of the divalent cations strontium and barium reflect on the other hand their high charge densities. Previous studies have shown that dibenzo-24-crown-8 can form bimetallic complexes with sodium and potassium $^{7}$. X-ray structural analysis of the potassium isothiocyanate complex has shown that the nitrogen atoms of the anions bridge two potassium ions ${ }^{19}$. In the metal picrate and perchlorate complexes it is unlikely that the anions can take part in this type of bonding. The ability of polyether $\mathbf{5}$ to form stable $1: 1$ complexes with salts of small cations such as sodium and strontium, can be attributed to the high flexibility of the 24-membered polyether ring. This flexible ligand may complex the metal cation by wrapping around it with a change in conformation.

The stoichiometry of the complexes was conductometrically confirmed. Molar conductivity measurements in methanol (listed in Table I) indicate that the alkali perchlorate and picrate complexes are 1:1 electrolytes, while the alkaline earth perchlorate complexes behave as $2: 1$ electrolytes.

\section{Ultraviolet spectra}

The ultraviolet spectra of the complexes dissolved in methanol give some evidence for the metalpolyether interactions. Changes in the shape of the absorption maximum of the free polyether in the region around $275 \mathrm{~nm}$ (though slight sometimes), hypsochromic shift or variations in absorbance can be attributed to complex formation (see Table II). As picrate salts absorb themselves in the region of

Table II. Ultraviolet and infrared data for macrocyclic polyethersa and their complexes.

\begin{tabular}{|c|c|c|c|c|}
\hline Compound & $\begin{array}{l}\text { Ultraviolet datab } \\
\lambda_{\max }(\log \varepsilon)\end{array}$ & $v_{\text {as }}\left(\mathrm{Ar}-\mathrm{O}-\mathrm{CH}_{2}\right)$ & 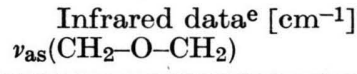 & $\omega, \tau\left(\mathrm{CH}_{2}\right)$ \\
\hline 1 & $275(3.70)$ & $1250 \mathrm{vs}, 1234 \mathrm{vs}$ & $1124 \mathrm{~s}$ & $970 \mathrm{w}, 968 \mathrm{~m}$ \\
\hline $\mathrm{Na}_{2}(\mathbf{1})_{3}$ (pic.) $)_{2}$ & $274(3.97), 278 \mathrm{sh}(3.97)$ & $1250 \mathrm{~s}, 1220 \mathrm{~m}$ & $1123 \mathrm{~m}$ & $964 \mathrm{w}, 940 \mathrm{vw}$ \\
\hline & $274(3.71)$ & $1256 \mathrm{vs}, 1230 \mathrm{vs}$ & $1130 \mathrm{vs}$ & $997 \mathrm{~m}, 932 \mathrm{~m}$ \\
\hline $\mathrm{Na}(2) \mathrm{ClO}_{4}$ & $274(3.72), 279(3.67)$ & $1255 \mathrm{~s}, 1220 \mathrm{~m}$ & $1129 \mathrm{vs}^{\mathrm{f}}$ & $953 \mathrm{~m}$ \\
\hline $\mathrm{K}(\mathbf{2}) \mathrm{ClO}_{4}$ & $273(3.75), 279(3.70)$ & $1250 \mathrm{vs}, 1213 \mathrm{~s}$ & $1120 \mathrm{vs}^{f}$ & $956 \mathrm{~m}, 940 \mathrm{~m}$ \\
\hline $\mathrm{Rb}(2) \mathrm{ClO}_{4}$ & $274(3.72), 279(3.66)$ & $1250 \mathrm{vs}, 1216 \mathrm{~s}$ & $1128 \mathrm{vs}^{\mathrm{p}}$ & $960 \mathrm{~m}, 954 \mathrm{~s}, 940 \mathrm{~m}$ \\
\hline $\mathrm{Ca}(2)\left(\mathrm{ClO}_{4}\right)_{2}$ & $274(3.72)$ & $1252 \mathrm{~s}, 1209 \mathrm{~s}$ & $1115 \mathrm{vs}^{\mathrm{P}}$ & $970 \mathrm{~m}, 954 \mathrm{~s}$ \\
\hline $\mathrm{Sr}(2)\left(\mathrm{ClO}_{4}\right)_{2}$ & $272 \operatorname{sh}(3.68), 276(3.69)$ & $1250 \mathrm{~s}, 1202 \mathrm{~s}$ & $1110 \mathrm{vs}^{\mathrm{f}}$ & $962 \mathrm{~m}, 948 \mathrm{~m}$ \\
\hline $\mathrm{Ba}(2)\left(\mathrm{ClO}_{4}\right)_{2}$ & $272(3.51), 277.5(3.48)$ & $1245 \mathrm{~s}, 1198 \mathrm{~m}$ & $1110 \mathrm{vs}^{\mathrm{f}}$ & $958 \mathrm{~m}, 935 \mathrm{~s}, 924 \mathrm{~m}$ \\
\hline $\mathrm{Na}(2)$ pic. & $273(3.86), 279 \mathrm{sh}(3.81)$ & $1256 \mathrm{vs}, 1222 \mathrm{~s}$ & $1130 \mathrm{vs}$ & $960 \mathrm{~m}, 949 \mathrm{~m}, 940 \mathrm{~m}$ \\
\hline $\mathbf{K}(\mathbf{2})$ pic. & $273(3.85), 279(3.79)$ & $1250 \mathrm{vs}, 1210 \mathrm{~s}$ & $1123 \mathrm{vs}$ & $960 \mathrm{~m}, 950 \mathrm{~s}$ \\
\hline $\mathrm{Rb}(\boldsymbol{2})$ pic. & $273(3.86), 279 \mathrm{sh}(3.80)$ & $1250 \mathrm{vs}, 1215 \mathrm{~m}$ & $1130 \mathrm{vs}$ & $965 \mathrm{~m}, 943 \mathrm{~m}$ \\
\hline $\mathrm{Ca}(\mathbf{2})$ (pic.) 2 & c & $1250 \mathrm{vs}, 1210 \mathrm{~m}$ & $1124 \mathrm{~s}$ & $950 \mathrm{br} \mathrm{m}$ \\
\hline $\operatorname{Sr}(2)$ (pic.) 2 & c & $1248 \mathrm{vs}, 1200 \mathrm{~m}$ & $1120 \mathrm{~s}$ & $940 \mathrm{~m}$ \\
\hline $\mathrm{Ba}(2)$ (pic.) 2 & c & $1250 \mathrm{~s}, 1202 \mathrm{w}$ & $1120 \mathrm{~s}$ & $960 \mathrm{~m}, 945 \mathrm{~m}$ \\
\hline 3 & $276(3.57), 280(3.56)$ & $1235 \mathrm{~s}$ & $1140 \mathrm{br} \mathrm{s}$ & $988 \mathrm{~m}, 940 \mathrm{w}$ \\
\hline $\mathrm{Na}(3)$ pic. & $271(3.74), 278 \operatorname{sh}(3.72)$ & $1240 \mathrm{br} \mathrm{s}$ & $1125 \mathrm{~s}$ & $998 \mathrm{~m}, 985 \mathrm{~m}, 940 \mathrm{w}$ \\
\hline $\mathbf{K}(\mathbf{3})$ pic. & $271(3.68), 278 \operatorname{sh}(3.66)$ & $1235 \mathrm{br} \mathrm{s}$ & $1124 \mathrm{~s}$ & $995 \mathrm{w}, 985 \mathrm{~m}, 940 \mathrm{w}$ \\
\hline $\mathrm{Ba}(\mathbf{3})$ (pic. $)_{2}$ & c & $1240 \mathrm{~m}, 1230 \mathrm{sh}$ & $1118 \mathrm{~m}$ & $997 \mathrm{~m}, 983 \mathrm{w}, 940 \mathrm{w}$ \\
\hline 4 & d & $1263 \mathrm{~s}, 1238 \mathrm{br} \mathrm{s}$ & $1140 \mathrm{vs}$ & $1000 \mathrm{w}, 980 \mathrm{w}, 958 \mathrm{w}$ \\
\hline $\mathrm{Ba}(4)$ (pic. $)_{2}$ & c & $1260 \mathrm{br} \mathrm{s}$ & $1138 \mathrm{~m}, 1124 \mathrm{~m}$ & $960 \mathrm{w}, 940 \mathrm{vw}$ \\
\hline & $276(3.64)$ & $1255 \mathrm{vs}, 1223 \mathrm{~s}$ & $1140 \mathrm{sh}, 1125 \mathrm{vs}, 1100 \mathrm{~s}$ & $960 \mathrm{~s}, 938 \mathrm{~m}, 922 \mathrm{~s}$ \\
\hline $\mathrm{Na}(5) \mathrm{ClO}_{4}$ & $275(3.67)$ & $1255 \mathrm{~s}, 1190 \mathrm{~m}$ & $1140 \mathrm{~m}, 1115 \mathrm{sh}^{\mathrm{f}}$ & $940 \mathrm{w}, 930 \mathrm{w}$ \\
\hline $\mathrm{Sr}(\overline{\mathbf{b}})\left(\mathrm{ClO}_{4}\right)_{2}$ & $276(3.67)$ & $1250 \mathrm{~s}, 1204 \mathrm{~m}$ & $1142 \mathrm{~s}, 1118 \mathrm{vs}^{\mathrm{f}}$ & $937 \mathrm{~m}$ \\
\hline $\mathrm{Ba}(5)\left(\mathrm{ClO}_{4}\right)_{2}$ & $276(3.60)$ & $1255 \mathrm{~s}, 1190 \mathrm{~m}$ & $1140 \mathrm{sh}, 1110 \mathrm{vs}^{\mathrm{f}}$ & $942 \mathrm{~m}, 917 \mathrm{w}$ \\
\hline $\mathrm{Na}(5)$ pic. & $271.5(3.83)$ & $1258 \mathrm{vs}, 1198 \mathrm{~m}$ & $1135 \mathrm{~s}, 1120 \mathrm{~s}, 1105 \mathrm{~s}$ & $934 \mathrm{~m}$ \\
\hline K(5) pic. & $270(3.83)$ & $1257 \mathrm{vs}, 1210 \mathrm{~s}$ & $1143 \mathrm{~m}, 1124 \mathrm{~s}, 1114 \mathrm{~s}$ & $940 \mathrm{~m}, 916 \mathrm{w}$ \\
\hline $\mathrm{Rb}(\mathbf{5})$ pic. & $271(3.83)$ & $1257 \mathrm{vs}, 1214 \mathrm{~s}$ & $1138 \mathrm{sh}, 1125 \mathrm{~s}, 1115 \mathrm{~s}$ & $942 \mathrm{~m}, 910 \mathrm{w}$ \\
\hline $\operatorname{Sr}(5)$ (pic.) 2 & c & $1250 \mathrm{vs}, 1208 \mathrm{~s}$ & $1112 \mathrm{~m}, 1075 \mathrm{~s}$ & $941 \mathrm{~m}, 914 \mathrm{~m}$ \\
\hline $\mathrm{Ba}(5)($ pic.) 2 & c & $1250 \mathrm{sh}, 1190 \mathrm{w}$ & $1114 \mathrm{~m}, 1098 \mathrm{~m}$ & $944 \mathrm{w}, 910 \mathrm{w}$ \\
\hline
\end{tabular}

a Some results reported by other workers, included for the sake of comparison; b In methanol, 250-300 $\mathrm{nm}$ region; c Region obscured by picrate absorption; d Too insoluble for measurement; $\mathrm{kBr}$ pellets, Key : w, weak;

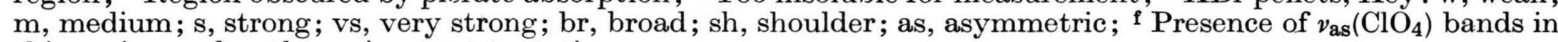
this region makes the assignment tentative. 
270-290 nm, the qualitative detection of complexing with macrocyclic polyethers is in this case limited. That is particularly evident when the spectra of the alkaline earth picrate complexes are considered.

The spectra of solutions of alkyl substituted aromatic macrocyclic polyethers 3 and 4 and various metal salts show that interactions between polyethers and metal salts can take place in alcoholic solution even when it was not possible to isolate the complexes in crystalline form.

Bis(4-hexadecylbenzo)-18-crown-6 (4) is almost insoluble in methanol at room temperature. By the addition of all the alkali and alkaline earth perchlorates and picrates its solubility is greatly increased. The spectra of these solutions show that complex formation is responsible for the increased solubility. The effect of some metal salts on the ultraviolet spectrum of polyether 4 is shown in Fig. 2.

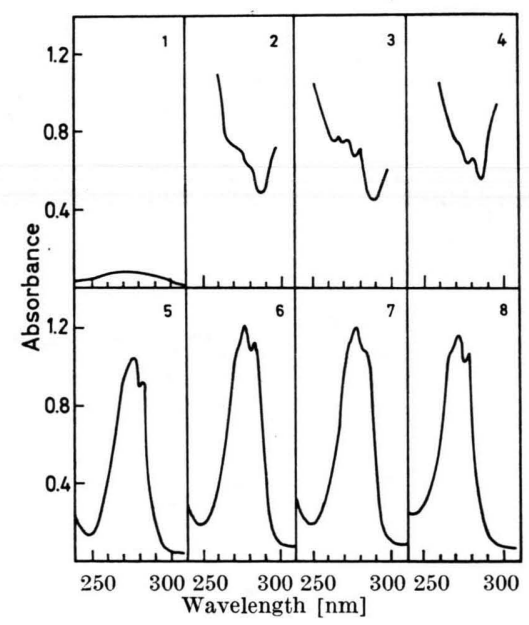

Fig. 2. Effect of some alkali and alkaline earth perchlorates and picrates on the ultraviolet spectrum of bis(4-hexadecylbenzo)-18-crown-6 (4) in methanol at $25{ }^{\circ} \mathrm{C}$. Polyether concentration $(1.5-1.7) \times 10^{-4} \mathrm{M}$ and metal salt concentration $\left.(3.0-4.0) \times 10^{-4} \mathrm{M}: 1\right)$ saturated solution of $4 ; 2-8$ ) solutions of metal salts and polyether 4: 2) Na picrate; 3) $\mathrm{K}$ picrate; 4) $\mathrm{Rb}$ picrate; 5) $\mathrm{NaClO}_{4}$; 6) $\mathrm{KClO}_{4}$; 7) $\mathrm{RbClO}_{4}$; 8) $\mathrm{Ba}\left(\mathrm{ClO}_{4}\right)_{2}$.

\section{Infrared spectra}

Significant differences between the infrared spectra of macrocyclic polyethers and their complexes may be noticed. The greatest changes are observed in the region $1200-900 \mathrm{~cm}^{-1}$ where bonds arising from various modes of vibration of ether and methylene groups are present (see Table II).
The infrared spectra of the complexes of bis(3,5-di-tert-butylbenzo)-18-crown-6 and bis(4-hexadecylbenzo)-18-crown-6 are very complex but different from the spectra of the metal salt and free ligand. The free macrocyclic polyethers exibit one or two $v_{\text {as }}\left(\mathrm{Ar}-\mathrm{O}-\mathrm{CH}_{2}\right)$ bands at $1260-1220 \mathrm{~cm}^{-1}$. Upon complex formation these bands are shifted to lower energy by $10-30 \mathrm{~cm}^{-1}$. Regularly, the band at lower energy is strongly shifted and sometimes becames noticeable weak. The $v_{\text {as }}\left(\mathrm{CH}_{2}-\mathrm{O}-\mathrm{CH}_{2}\right)$ band present in the polyethers at $1140-1125 \mathrm{~cm}^{-1}$, upon complexing is also shifted to lower energy by $20 \mathrm{~cm}^{-1}$. Complexes with dibenzo-24-crown-8 have two or three bands associated with this vibration. The strong bands attributed to the perchlorate group in the metal perchlorate complexes greatly obscure this region. Considerable differences are observed in the $1100-900 \mathrm{~cm}^{-1}$ region which contains bands attributed to wag, twist and rock modes of vibration of the methylene groups. Less restriction on the coupling of these vibrational modes in the complexes is probably due to some bonding between the oxygen atoms of the polyether ring and the metal cation. The great similarity in the spectra of all alkali and alkaline earth metal complexes with the macrocyclic polyethers indicates that metal-ether interactions are essentially the same.

\section{${ }^{1} H \mathrm{NMR}$ spectra}

Unfortunately, most of the complexes are too insoluble in $\mathrm{CDCl}_{3}$ for observing ${ }^{1} \mathrm{H}$ NMR spectra. Only for the complexes of sodium perchlorate and picrate with dibenzo-24-crown-8 satisfactory spectra have been obtained. For all protons chemical shift differences between complexed and noncomplexed polyether are visible (see Table III). In the complexes the so-called "inner" $\mathrm{CH}_{2}-\mathrm{O}-\mathrm{CH}_{2}$ polyether ring protons are shifted slightly upfield by $6-9 \mathrm{cps}$, while the "outer" $\mathrm{Ar}-\mathrm{O}-\mathrm{CH}_{2}$ protons, as well as the aromatic protons of the polyether molecule, are shifted downfield by 8-10 and 8-13 cps, respectively. Presumably, this deshielding is caused by the inductive effect of the sodium ion on the polyether molecule. Comparison with the spectra of sodium tetraphenylborate complex with dibenzo-24-crown-8 indicates that the anion has an important role in the resulting chemical shift of the polyether ring protons. The close proximity of the polyether molecule to the aromatic rings of the anion causes 
a stronger upfield shift of the inner protons and a somewhat lesser one of the outer protons in spite of the complexation with the alkali cation which in itself would induce a downfield shift due to the increased electronegativity of the oxygen atoms. The same situation was observed in the complexes of fluorenyl alkali salts ${ }^{20}$.

We would like to thank Dr. B. KoJIć-Prodić, the Solid State Department of Institute Rudjer Bošković, for $\mathrm{x}$-ray powder photographs.

1 LJ. TušEK, Dissertation, University of Zagreb, 1975.

2 C. J. Pedersen, J. Amer. Chem. Soc. 89, 7017 [1967].

3 C. J. Pedersen and H. K. Frensdorf, Angew. Chem. Int. Ed. 11, 16 [1972].

4 A. Cassol, A. Seminaro, and G. De Paoli, J. Inorg. Nucl. Chem. Letters 9, 1163 [1973].

5 R. B. King and P. R. Heckley, J. Amer. Chem. Soc. 96, 3118 [1974].

6 A. C. L. Su and J. F. Weiner, Inorg. Chem. 7, 176 [1968].

7 N. S. Poonia and M. R. Truter, J. Chem. Soc. (Dalton) 1973, 2062.

8 N. S. Poonia, J. Amer. Chem. Soc. 94, 1012 [1974].

9 D. G. Parsons, M. R. Truter, and J. N. WingFIELD, Inorg. Chim. Acta 14, 45 [1975].

10 N. S. Poonia, J. Inorg. Nucl. Chem. 37, 1855 [1975].

11 J. M. Lehn, M. R. Truter, W. Simon, W. E. Morf, P. Ch. Meier, R. M. Izatt, D. J. Eatough, and J. J. Christensen, Struct. Bonding 1973, 16.

12 R. WinkLer, Struct. Bonding 10, 1 [1972].
Table III. ${ }^{1} \mathrm{H}$ NMR spectra* of dibenzo-24-crown-8 and its complexes.

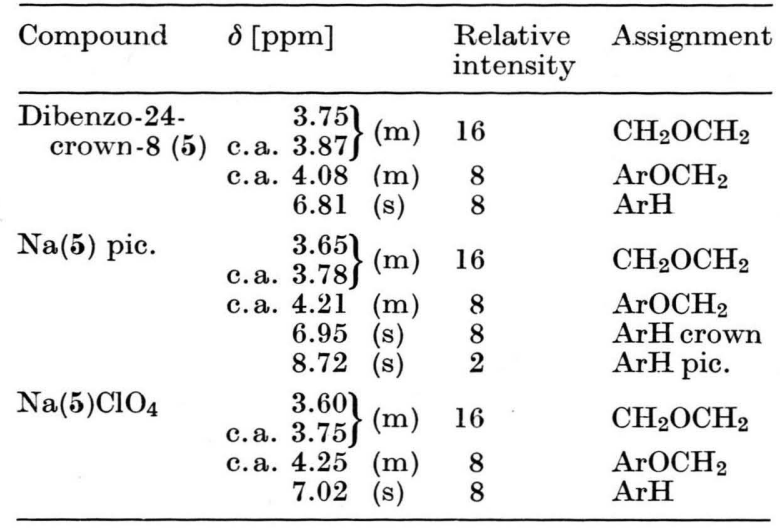

* Values relative to TMS internal reference, in $\mathrm{CDCl}_{3}$.

13 D. De Vos, J. Van Daalen, A. C. Knegt, Th. C. Van Heyningen, L. P. Otto, M. W. Vonk, A. J. M. WiJsman, and W. L. Driessen, J. Inorg. Nucl. Chem. 37, 1319 [1975].

14 H. K. Frensdorf, J. Amer. Chem. Soc. 93, 600 [1971]; 93, 4684 [1971].

15 P. R. Danesi, H. Meider-Goričan, R. Chiarizia, and G. Scibona, J. Inorg. Nucl. Chem. 37, 1479 [1975].

16 LJ. Tušek, Com. Naz. Energ. Nucl. (Rapp. Tec.) 1974, RT-CHI 74(5), 1.

17 D. Bright and M. R. Truter, J. Chem. Soc. (B) $1970,1544$.

18 LJ. TuŠEk, P. R. Danesi, and R. Chiarizia, J. Inorg. Nucl. Chem. 37, 1538 [1975].

19 M. Mercer and M. R. Truter, J. Chem. Soc. (Dalton), 1973, 2469.

20 K. H. Wong, G. Konizer, and J. Smid, J. Amer. Chem. Soc. 92, 666 [1970]. 